\title{
1. Introduction: What do we know about international joint ventures?
}

\section{INTRODUCTION}

The proliferation of inter-firm collaboration has been well documented (e.g. Hergert and Morris, 1988; Hagedoorn, 1996; Gomes-Casseres, 1996; Beamish and Delios, 1997a; Glaister and Buckley, 1994; Glaister et al. 1998), with alliance activity now a crucial part of the strategy of many firms (Harrigan, 1985, 1988a; Bleeke and Ernst 1993a,b). Competitive advantage increasingly depends not only on a company's internal capabilities but also on the types of alliances and the scope of its relationships with other companies (Parkhe, 1991). These trends signal the need to understand the nature of inter-firm collaborative activity, not least because it has a profound effect on the practising managers (Buckley and Young, 1993: 215).

The focus of this book is a subset of strategic alliance activity - that of international equity joint ventures (JVs). These involve two or more legally distinct organizations (the parents), each of which invests in the venture (the child) and actively participates in the decision-making activities of the jointly owned entity. A JV is considered to be international if at least one partner has its headquarters outside the venture's country of operation or if the JV has a significant level of operation in more than one country.

International joint ventures (IJVs) have been described as 'a logical and timely response to intense and rapid changes in economic activity, technology, and globalisation' (Doz and Hamel, 1998: xiv). Doz and Hamel argue that globalization has opened the 'race for the world' as firms enter once-closed markets and pursue untapped opportunities. At the same time the "race for the future' compels firms to discover new market opportunities, new solutions for customers, and new answers to poorly met needs. Moreover, few firms can now create and deliver products and services on their own, let alone control leading-edge technologies: technologies are seldom controlled by single firms; significant technological development depends on collaborative activity.

IJVs do not occur by chance; rather they are the outcome of a company decision, hence certain goals and motives must be present to justify creating an IJV. It cannot be assumed that IJVs are always prompted by a single aim, 
however, they are more likely to be the result of a number of different motives. Furthermore, the expectations and goals that led to the creation of the IJV constitute the rational measures for evaluating the success or failure of the IJV (Buchel et al., 1998: 15-16).

The major dimensions of JV investigation identified in the prior literature (summarized by Parkhe, 1993) are: motives for JV formation, partner selection, management control and JV performance. These four research dimensions are adopted as the core elements of this study. While these four dimensions constitute discrete aspects of JV activity they also represent a set of integrated relationships. The empirical research reported in this book considers each of the discrete dimensions and also investigates a set of interrelationships among these dimensions.

There is a vast amount of literature on joint ventures and alliances, although this literature has been criticized for being non-cumulative and unsynthesized (Parkhe, 1993). In the following sections we set out the context for the rest of the book by examining the core dimensions of IJVs. We then set out the domain of the study.

\section{WHAT DO WE KNOW ABOUT INTERNATIONAL JOINT VENTURES?}

The first point to note is that IJVs are simply one business arrangement among many. The choice of an IJV is made against the competing alternatives of licensing arrangements, mergers, wholly owned subsidiaries, foreign direct investment and looser 'non equity' collaborations (Buckley and Casson, 1998a). Consequently, it is essential to remember that the normal issues of business practice apply to IJVs as to all forms of business institutions and practices. The following section makes this point in detail. Thereafter, we examine the unique or unusual issues involved in IJVs and the extent to which special explanations are required for their existence. We then produce a matrix of 'issues by explanation'. This matrix is capable of further refinement as we shall see.

\section{IJVs AS BUSINESS PRACTICE AND BUSINESS INSTITUTIONS}

This section seeks to show that many of the features of IJVs are amenable to standard analysis using regular business theories and approaches - economics, finance and organization theory. Standard techniques of analysis are 
as applicable to IJVs as to other business arrangements. Intrinsic to this argument is the view that standard microeconomic analysis is relevant to IJVs. It can be shown that the search for economies of scale and market power provide the underpinning for the suggestion that IJVs provide increasing returns to scale analogous to any business expansion programme. In addition IJVs are a powerful technique for reducing transaction costs in situations where there are barriers to other forms of expansion (such as mergers) (Buckley and Casson, 1998a). The Resource Based Theory of the firm is also relevant and many attempts have been made to integrate this approach with transactions cost economics.

The rules of finance also apply to IJVs. IJVs are sought, just like other real options, because the risk/return trade-off is thought to be favourable. Here, as elsewhere, the flexibility of IJVs allows them to be converted either to a fully owned investment or liquidated (by sale to the partner, perhaps) (Buckley and Casson, 1998b). Valuation problems arise in IJVs, both as a partner selection issue, as a management problem and as an issue in liquidation, sale or conversion to a wholly owned operation.

Organization theory, too, has an important bearing on IJVs. The role of learning is critical in many IJVs (Gomes-Casseres, 1996) and life-cycle concepts are useful in many situations.

In terms of the techniques needed to analyse IJVs, in addition to those deriving from economics, finance and organization theory, it will be particularly appropriate to examine game theory and agency theory. Game theory lends itself to IJVs because of the crucial notion that IJVs involve at least two players - the parents - with possibly a third player if the IJV can be considered an independent player. Agency theory is relevant because of the remoteness of the decision-makers (the managers of the IJV) from the owners (the parents).

It is therefore essential that, before considering the 'special issues' involved in IJVs and the need for unique theories, techniques and explanations, we delimit the area of 'specialness' by utilizing extant methods of analysis. These are summarized in Table 1.1.

\section{SPECIAL ISSUES IN IJVs}

IJVs involve managing across the borders of the unitary firm. They therefore raise a number of special issues, in particular motives for formation, partner selection, management, control and performance.

The question of motives for establishing IJVs requires special attention insofar as the choice of form of joint venture can be contrasted with other means of achieving corporate objectives. IJVs thus can be analysed by 
Table 1.1 Relevance of received theory

\begin{tabular}{ll}
\hline Economics & $\begin{array}{l}\text { Economies of scale and scope } \\
\text { Increasing/consolidating market } \\
\text { power }\end{array}$ \\
& Increasing returns \\
TCE (Transaction Cost Economics) & $\begin{array}{l}\text { Reducing transaction costs } \\
\text { (versus agency costs) }\end{array}$ \\
Resource Based Theory of the firm & Accessing competencies \\
Finance & Return \\
& Risk \\
& Valuation \\
Organization theory & IJVs as real options \\
& Learning \\
& Reduce resource dependence \\
& Life cycle models
\end{tabular}

reference to the alternatives forgone - takeover, greenfield (wholly owned venture), licensing. Each of these forms will have advantages and disadvantages as compared to IJVs and these need to be carefully clarified and quantified. Essentially, these forms are horizontal, market access alternatives. Similar analyses can be performed for vertical IJVs. Other motives may need more extensive analysis.

The choice of partner is clearly a major issue in IJVs. Partner selection will be a key factor determining the success (performance) of the IJV. This is analogous to, but not congruent with, a takeover. In a takeover, complementarities may be vital, but a takeover may be effected in order to close down or remove the victim. The key issue in takeovers is valuation, in IJVs it is negotiation. In a takeover, management becomes unitary (hierarchical) whereas in an IJV, it is perforce co-operative.

This leads to the view that management is (or needs to be) different from that in the unitary firm. IJVs are to some degree exceptional in the context of a stereotyped hierarchically organized firm. Directives from top-down are clearly not a viable way of managing beyond the firm's boundaries, and some modification of management practice and style are necessary.

This is closely related to the notions around 'control' in the IJV. Work has focused on the extent of control, the mechanisms by which it has been exercised and the focus of such control. It may be suggested that control of an IJV is more difficult than in a normal ownership situation and thus the decisions of the IJV are to some extent outside the determination of the (any) parent. Thus the parent has to design mechanisms into the structure and management of the 
IJV and, maybe, has to focus its control on a subset of these decisions. The subset chosen will reveal a great deal about the objectives and strategic direction that the parent wishes to achieve. There may, too, be a trade-off between extent of control and the degree of risk assumed by the parent.

Finally, the performance of IJVs may be difficult to evaluate. If the motive for establishment differs from straight profit - maximization, then perhaps the IJV should be judged against these objectives rather than a calculus of profits. Moreover, it may well be difficult to evaluate the profitability of an IJV in that it is not a free-standing entity and indivisibilities exist between its profits and those of its parents. The termination of an IJV may not be an indicator of failure - indeed it may connote success in that the objectives set for it have been achieved. If IJVs are judged as 'real options' (Buckley and Casson, 1998b; Kogut, 1991), then the taking up of the option by internalization may be entirely congruent with the parent's initial goals. IJVs, paradoxically, may be most successful when they are relatively short-lived! Given this, how can performance, at a given point of time, be meaningfully measured? Again, perhaps the only true measure is against an alternative business form. Table 1.2 examines special theories of IJVs correlating 'issues' with 'concepts'.

Table 1.2 can be collapsed into a more comprehensible two-by-two matrix examining the twin issues of entry and management and the two conceptual structures of 'international business' and 'international management', as shown in Table 1.3. International business is the set of concepts from transaction cost economics (Williamson, 1975, 1985) and internalization theory (Buckley and Casson, 1976; 1998a; 1998b). International management is the applied area of resource based theories of the firm (Grant, 1996). This simple division highlights the differences between the two most important explanatory approaches to IJVs. ${ }^{1}$

It will be noted that this is set up as a process in fixed stages and in a definite time sequence - motives, choice of partner/partnering, management, control (operation), performance (outcome). This framework can be a straitjacket for analysis. It has some similarities with the 'Uppsala' analysis of 'stages of international involvement' which was mistakenly taken by some as a determinate process. And here we go back to an old issue, that of models versus frameworks (Buckley, 1996). The analytic modelling of joint ventures and alliances focuses on isolation of a few key variables, particularly environmental variables, and predicting from the model the way in which the firm will behave (Buckley and Casson, 1996). This contrasts with the approach based on synthesis (for example Parkhe, 1993) which leaves the assumptions implicit and derives propositions from an extensive literature review.

The comparative perspective is particularly important in respect of JVs. In answering questions on why firms choose JVs or how successful they have been, it is essential to compare JVs with other institutional arrangements. In 
Table 1.2 Special theories of IJVs

\begin{tabular}{|c|c|c|c|c|c|}
\hline \multirow[b]{2}{*}{ Issues } & \multicolumn{5}{|c|}{ Concepts } \\
\hline & Internalization & $\mathrm{TCE}$ & $\begin{array}{l}\text { Resource based } \\
\text { theory of firm }\end{array}$ & $\begin{array}{l}\text { Strategic } \\
\text { management }\end{array}$ & $\begin{array}{l}\text { Organization } \\
\text { theory }\end{array}$ \\
\hline 1. Motives & $\begin{array}{l}\text { i. Benefits of } \\
\text { internalizing } \\
\text { intermediate goods } \\
\text { ii. Indivisibilities } \\
\text { iii. Barriers to merger. }\end{array}$ & $\begin{array}{l}\text { Opportunism } \\
\text { Bounded } \\
\text { rationality } \\
\text { Small numbers } \\
\text { Asset specificity }\end{array}$ & $\begin{array}{l}\text { Leverage Internal } \\
\text { resources } \\
\text { (capabilities) }\end{array}$ & $\begin{array}{l}\text { Speed to market } \\
\text { Risk reduction } \\
\text { Scale economics }\end{array}$ & $\begin{array}{l}\text { Reduce } \\
\text { resource } \\
\text { dependency }\end{array}$ \\
\hline $\begin{array}{l}\text { 2. Partnering - } \\
\text { choice of partner }\end{array}$ & $\begin{array}{l}\text { Potential benefits } \\
\text { of internalization and } \\
\text { indivisibilities }\end{array}$ & $\begin{array}{l}\text { Partner choice } \\
\text { mitigates effects } \\
\text { of (i) above }\end{array}$ & $\begin{array}{l}\text { Compatible } \\
\text { management } \\
\text { possession of } \\
\text { complementary } \\
\text { capabilities }\end{array}$ & $\begin{array}{l}\text { Compatibility of } \\
\text { goals } \\
\text { Task related } \\
\text { complementarity }\end{array}$ & $\begin{array}{l}\text { Key is reduction } \\
\text { of dependency } \\
\text { (trade-off with } \\
\text { management } \\
\text { problems) }\end{array}$ \\
\hline 3. Management & $\begin{array}{l}\text { Co-operation: } \\
\text { Mutual forbearance } \\
\text { Commitment } \\
\text { Trust }\end{array}$ & $\begin{array}{l}\text { Trust as TC } \\
\text { reducing element }\end{array}$ & $\begin{array}{l}\text { Transmit and } \\
\text { receive capabilities }\end{array}$ & Similar goals & $\begin{array}{l}\text { Network } \\
\text { management }\end{array}$ \\
\hline $\begin{array}{l}\text { 4. Control - } \\
\text { Bases } \\
\text { Extent } \\
\text { Focus } \\
\text { Mechanisms }\end{array}$ & $\begin{array}{l}\text { Comparative } \\
\text { perspective }\end{array}$ & $\begin{array}{l}\text { Trade off control } \\
\text { versus market } \\
\text { elements }\end{array}$ & $\begin{array}{l}\text { Choose } \\
\text { optimum means } \\
\text { of accessing } \\
\text { resources }\end{array}$ & $\begin{array}{l}\text { Strategic dissonance } \\
\text { between partners }\end{array}$ & $\begin{array}{l}\text { Variety of } \\
\text { means of } \\
\text { control power } \\
\text { structure }\end{array}$ \\
\hline $\begin{array}{l}\text { 5. Performance } \\
\text { duration }\end{array}$ & $\begin{array}{l}\text { 'Flexibility' necessarily } \\
\text { limited }\end{array}$ & $\begin{array}{l}\text { Inherently } \\
\text { unstable? }\end{array}$ & $\begin{array}{l}\text { Access to resource } \\
\text { is key } \\
\text { Lasts so long as } \\
\text { effective means of } \\
\text { access }\end{array}$ & $\begin{array}{l}\text { Strategic choice } \\
\text { changes over time }\end{array}$ & \\
\hline
\end{tabular}


Table 1.3 Key issues in IJV research

\begin{tabular}{lll}
\hline & International business & International management \\
\hline Entry & $\begin{array}{l}\text { Benefits of internalizing } \\
\text { intermediate goods versus } \\
\text { barriers to merger }\end{array}$ & $\begin{array}{l}\text { Complementarity of } \\
\text { capabilities and compatibility } \\
\text { of goals }\end{array}$ \\
$\begin{array}{l}\text { Operation } \\
\text { and } \\
\text { management }\end{array}$ & $\begin{array}{l}\text { Reduce co-ordination costs } \\
\text { through increasing trust } \\
\text { and growth in commitment }\end{array}$ & $\begin{array}{l}\text { cansabilities } \\
\text { cand receive }\end{array}$ \\
\hline
\end{tabular}

practice, this introduces difficulties, because JVs are an intermediate state, between wholly owned subsidiaries and looser market based arrangements like licensing. Analytical techniques are much better at examining extreme solutions or outliers, rather than intermediate, moderate, middling outcomes.

There is a further, related problem in the analysis of IJVs and alliances which directly relates to issues of time, and that is longevity. This is not new. Alfred Marshall himself said 'For the element of time, which is the centre of the chief difficulty of almost every economic problem' (preface to first edition of Principles of Economics 1890 (p. vii in 8th edition 1930)). As mentioned above, the most successful joint ventures and alliances may be the most shortlived. Flexibility in strategy may require rapid and frequent moves into and out of a series of joint ventures.

A successful analysis of JVs must not then fall victim to the tyranny of time. But we must acknowledge that time is a crucial element in the approach to JVs. Should we then split up the above process into separate pieces? Or is there a more subtle way of encompassing the time dimension?

There are techniques to compress time - notions of sunk costs, stocks rather than flows, discounting future benefits and real options are all attempts to capture the shadow of the future. Perhaps it is dissatisfaction with these techniques which leads management theorists to despair of 'models' and turn to 'frameworks'?

A related difficulty is that of 'learning'. This needs to be encompassed both within a single joint venture and across multiple joint ventures (leading to the notion of 'joint venture sophisticated firms'). Feedback mechanisms may, again, be regarded as an inadequate response to learning, but if we can more carefully specify what precisely the learning is about, then maybe progress can be made (Casson, 1994).

Perhaps time-dependent processes require new forms of analysis, such as notions of irreversibility and path dependence which need to be fully integrated into JV theory. 
A further philosophical issue arises in assessing joint ventures, which is not unique to them. This is the appropriateness of a 'Platonic' method versus an 'Aristotelian' method. Platonists prefer to compare situations and institutions with the (Platonic) ideal. An example of this is the standard of 'perfect competition' in economics. Aristotelians prefer a concrete comparison. This is raised in Williamson's (1996) idea of 'remediableness'. A situation is 'remediable' in the following terms: 'Within the feasible subset, the relevant test [for remediableness] is whether (1) an alternative can be described that (2) can be implemented with (3) expected net gains.' (Williamson 1996: 210).

This has strong parallels with Hirschman's (1970) notion of repairable lapses of economic actors. We should beware of comparing JVs with a Platonic ideal, unless we use this criterion everywhere. There is at least a suggestion in the literature that IJVs are often compared against an ideal institutional alternative rather than applying the remediableness criterion.

\section{CONCEPTUAL INNOVATIONS IN ANALYSING IJVs}

Because of the argument that joint ventures are special and require special explanations, several relatively new concepts have been developed to tackle the above issues. (Perhaps it is more accurate to state that more weight has been put on several extant concepts felt to be particularly relevant to IJVs.) With Ockham's razor in mind, we should beware the proliferation of concepts and introduce new ones only when absolutely necessary.

Among the new concepts are co-operation (variously defined), trust, culture, learning and networks.

One further issue arises which leads us into the realm of research method. This is the question of whether 'objective' or 'subjective' explanation is necessary for IJVs. Is it possible to have a satisfactory explanation of the structure, motives, management and performance of IJVs from secondary data alone? Or is there something inherent in IJVs which requires knowledge of the motivations, outlook and 'native categories' (Buckley and Chapman, 1998) of the individual manager?

Managers are important in international business theory (Buckley, 1996). They make judgements in the face of uncertainty and therefore, sometimes, they make mistakes. The information on which they work and the conceptual frameworks within which they operate are currently subject to intense analysis (Buckley and Carter, 1999; Buckley and Chapman, 1996; 1997).

Buckley and Casson (1988) see joint ventures as an institutional arrangement to mitigate the worst consequences of mistrust. They represent a compromise contractual arrangement for minimizing the transactions costs of a complex sequence of interactions between the firms. The JV allows the interaction of a mutually positive kind based on the exercise of 'mutual forbearance'. The JV is, 
however, only the formal structure which permits this behaviour. It is the behaviour (mutual forbearance) which brings the benefit, not the structure (JV) per se. On this reading, JVs are a permissory institution. The research agenda arising from this goes on to identify the types of environmental conditions that lead to JVs. These key variables are not purely economic, but include technological and cultural elements. Key determinants include obstacles to licensing (lack of patent rights, uncertainty about technological competence), obstacles to IJVs (cultural distance) and obstacles to merger (protection of the firm's independence, scope economies in technology) - all of which are clearly institutional comparators (Buckley and Casson, 1996). Buckley and Casson simplify the institutional choice by showing that joint ventures are likely to be chosen in intermediate market conditions (large volatile market or small stable market). These are precisely the areas where managerial judgement (or perception) of the relevant comparative costs are likely to be at their most critical.

- IJVs as 'compromise' (between market modes e.g. licensing and takeover); 'intermediate state'

- Use in large but volatile markets and stable but small markets

- IJVs as a 'real option'; cultural benefits of IJVs (versus hostile takeover)

- Extreme values do not capture IJVs

\section{MOTIVES}

Following Gomes-Casseres (1996) we can identify three major motives for the formation of alliances and joint ventures. These are: (1) supply based alliances, which function along the supply line and involve resource transfers beyond simple exchange relationship (finance, design, management skills and technology may flow between the partners) in order to reduce transaction costs and to enhance innovatory relationships. (2) Alliances based on corporate learning which enable the transfer of tacit knowledge and the creation of cross-company terms, perhaps across a technological frontier. (3) Market based reasons. This may include the traditional cartel and reducing the speed to market (Lei and Slocum, 1991). Motives for IJV formation are summarized as follows:

- Foreign Market Entry v Non-Market Entry

- IJVs as Entry Choice: - Learning

- Reducing competition

- Diversification

- Cost sharing

- Regulatory restrictions

- Vertical IJVs (reduce TCs) 
A crucial distinction in motives for IJVs arises between market entry and nonmarket entry motives. Buckley and Casson (1998a) analyse market entry motives where markets are differentiated by size and volatility. IJVs are found to be an 'intermediate mode' used where markets are growing but not overwhelmingly large (where FDI and merger are preferred) or small (where licensing is optimal). They are also useful in large but volatile markets, where their role as an 'option' on deeper involvement or withdrawal is at a premium. However, a number of other key motives have been identified in the literature. These include learning, reducing competition, diversification, cost sharing (including $\mathrm{R} \& \mathrm{D}$ costs) and regulatory restrictions. At least a modification of the standard market entry analysis is required where such motives are important.

In addition, we must not ignore vertically linked IJVs. The spectrum of choice runs through full integration, through quasi vertical integration (Blois, 1972), IJVs and alliances, long-term contracting (relational contracting) to simple buyer-seller relationships. These issues are well explored in the literature.

\section{PARTNERING}

The standard transaction cost/internalization theory argument on choosing joint venture partners is that internalizing one or more markets in intermediate goods provides benefits for the IJV, but that there must also be significant barriers to merger (Buckley and Casson, 1988). The resource based theory of the firm suggests similarities in management strategy combined with complementarities (differences) in capabilities. In the language of strategic management, this represents compatibility of goals and task-related complementarities. Both vertical and horizontal complementarity may produce an IJV. Horizontal IJVs pose competition issues and raise strategic questions arising from competitors in one area co-operating in another. Cartels rather than IJVs may be the appropriate nomenclature for JVs which have market-based rationales.

- 'Differences' versus 'similarities'

- Complementary capabilities and similarities in management strategy

- Impact of competitors (alliance capitalism); cultural influences

- Dynamic aspects - management and trust

Collapsing the arguments (particularly of Porter and Fuller, 1986), we can suggest that four key elements may be involved in partner choice. 
1. The firms must have complementary capabilities.

2. The firms must have compatible (international) strategies.

3. At least in their current operating area, there must be a low risk of the partner becoming a competitor (although, of course, firms will compete and collaborate with firms in different products, segments and markets). There are issues here of 'reciprocal dependency' and 'hostages'.

4. The partnership may have a pre-emptive value in relation to competitors.

\section{MANAGEMENT}

It is clear that joint ventures need a different management approach from the unitary firm. Almost all works on IJV attribute immense importance to the growth of trust between partners - so much so that the study of trust and the mechanisms of inculcating trust have become a subject in their own right. Buckley and Casson (1988) take a theoretical approach and look for 'mutual forbearance' between the partners to produce a commitment to the joint venture, which then produces trust as an output. Trust can be an input too, as the transactions cost literature makes clear and surrogates for this may be involvement with previous IJVs (and JVs), and a declared similarity of goals. The dynamics of generating trust can be examined by deliberate looseness of contract to allow for growth in co-operation, by 'taking the easy decisions first' or by deliberate forgoing of the use of bargaining power (as exemplified by the initial shareholding - perhaps 50:50 rather than 60:40).

\section{CONTROL}

Issues on control are the bases of control, its extent, focus and the mechanisms by which it is exercised. The notion of parental control is to some extent a contradiction of co-operation but it must be recognized that both can co-exist and can be seen as separate domains by the managers involved (see Table 1.4).

Initial research on the extent of control as Child and Faulkner (1998) point out, saw control as a single, continuous variable. Consequently it could be plotted on a single continuum (for example dominant - shared - independent control). It was often taken as being dependent on centralization or on the location of decision making. This rather simplistic approach was replaced by a more differentiated view of control, examining the focus, mechanisms and bases of control.

A differentiated view of control sees parents as exercising control over a relatively wide or narrow range of the joint venture's activities (Geringer 
Table 1.4 Control

Extent

Focus Wide or Narrow?

Mechanisms

Bases
Control as single continuous variable?

Differentiated view - focus of control

Technology

Finance

Quality

Marketing issues

Management

Equity share

Key managers/directors

Formal contracts

Key inputs (e.g. technology)

Financial control

Control of communications

Capabilities

Strategies

Reciprocal dependencies

and Hebert, 1989). Parents may focus on financial control, control over technology, over quality or marketing issues or over the choice of senior management.

The mechanisms of control are varied, and also suggest the areas that the parents feel to be most important. They include:

- equity shareholding;

- appointment of the IJV's Board of Directors;

- appointment of key managers;

- control of key inputs, including technology;

- financial reporting, budgeting and rationing;

- control over communications.

The fundamental basis of control may be reduced to three:

1. In equity joint ventures, the (majority) equity share.

2. Willingness or ability to commit key resources to the IJV, including continuing operational support, and

3. Bargaining power.

The first two have a direct managerial and economic basis, the third takes on a socio-political dimension. 


\section{PERFORMANCE}

There are clearly difficult and unusual elements in assessing the performance of IJVs. The first is the obvious point that the goals of the partner can, and do, differ. Second, objective data on performance are difficult to gather. Ideally, the analysis should be conducted on a with IJV/without IJV comparison, but this is impossible. Third, a subjective analysis of how far the IJV has met its goals, is just that - subjective; and from whose point of view - the partners or the IJV management? In addition, studies of IJV performance have been obsessed with the relationship of performance with control.

The performance of IJVs should be compared with the results of acquisition or non-equity means of achieving the same goals.

It we take IJVs as a method of achieving market access - as one choice among several; then we can explain a great deal about them. Where motives are non-market access, we need to adopt a similar method to achieve further understanding. That is, we need to see IJVs as one choice among several in learning, reducing competition, diversification and cost sharing.

This list does not include vertical alliances as the key factors in the spectrum between full internalization, quasi-internalization (Blois, 1972), alliances, longterm contracting and simple market relations are well known.

\section{METHODOLOGY AND INTERRELATIONSHIPS}

Two further issues require clarification. The first is the appropriate methodology with which to tackle these issues. Here it is possible to fall into an arid debate between 'positivistic' approaches versus others. The 'native category' problem also bedevils the investigation of terms which may be imperfectly understood by the respondents (Buckley and Chapman, 1998). Interviews and even more so, questionnaires, need to be constructed so as to minimize the cultural distance between academic perception and participant understanding.

Research methods also need to comprehend interrelatedness. Bilateral relationships between variables (control and performance, for instance) are embedded in a nexus of causality which need careful investigation. A fruitful approach is the use of network theory, but often this can obfuscate rather than illuminate. Joint ventures frequently can only be understood in a wider picture of inter-firm relationships and untangling these is often a challenge in itself.

Many studies of IJVs suffer from problems with regard to the window of observation. As Figure 1.1 shows, many studies are a mix of observations of IJVs that (1) began during the observation period, (2) ended during the period, (3) both began and ended during the period and (4) persisted throughout the observation period and beyond. As Marshall noted, time often is the chief 


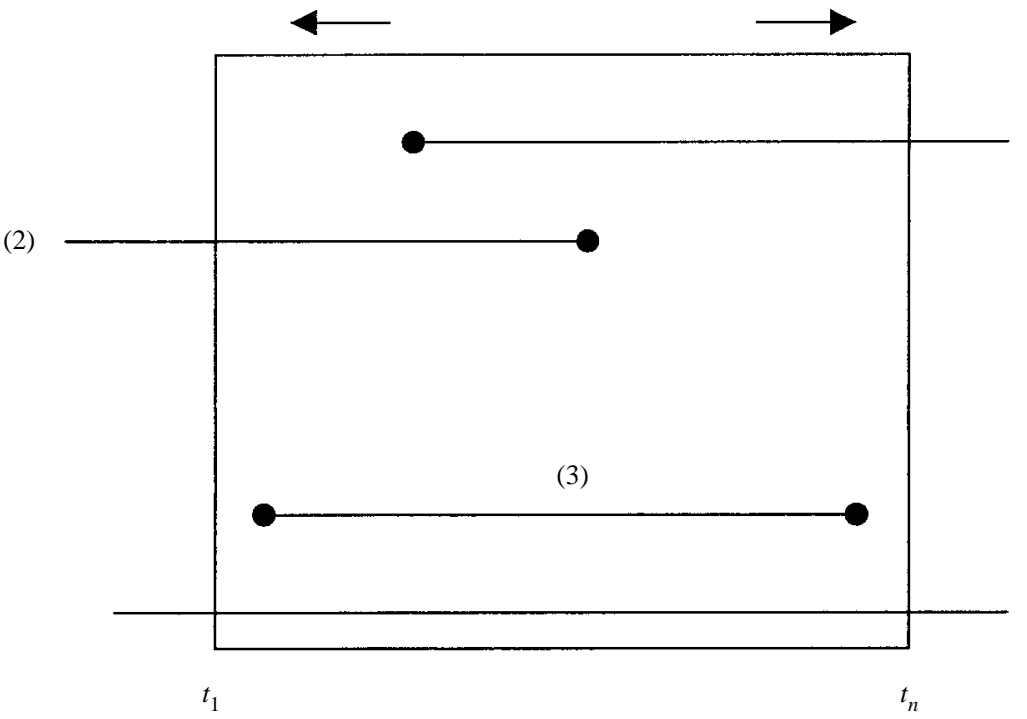

\section{Figure 1.1 IJVs: the time window of observation}

difficulty of analysis, particularly when performance issues are being investigated. A promising avenue here is to pay more attention to 'sunk costs' (Sutton, 1991), particularly as entry-deterrence mechanisms. This has the effect of producing a snapshot in time of a dynamic strategic process.

\section{CONCLUSIONS}

What do we know about joint ventures? The answer clearly is quite a lot. However, IJVs are not one phenomenon and there is not one single question which needs to be answered. One stance which is not justified is the 'Gee whiz, these things are so different' approach which cuts off JVs from the scope of conventional analysis. JVs and IJVs are institutional choices to achieve company goals just like any other form of business activity. They need to be evaluated in exactly the same way as more conventional modes of operation comparatively over time, over space (different countries) and against the counterfactual. Issues of time and time related variables do impact on the analysis, but not in ways that cannot be imaginatively handled.

There is not one simple overarching theoretical perspective designed for, and exclusively dealing with, IJVs. There has been some 'rush to empiricism' without a fully thought out theoretical structure in many cases. 
However, many issues centred on IJVs are explicable via conventional analysis.

We need to know far more about certain (interrelated) key variables (trust, opportunism, reciprocity, forbearance). Work on IJVs represents a research agenda, not yet fully accomplished. Concentration on the special areas of IJVs (motives, partnering, management, control and performance), perhaps sequentially, will lead us out of the morass which justifies the criticism that much of the work is 'non-cumulative'.

\section{DOMAIN OF THE STUDY}

This study focuses on a subset of strategic alliance activity - that of international equity joint ventures. As noted in the introduction, these involve two or more legally distinct organizations (the parents), each of which invests in the venture (the child) and actively participates in the decision-making activities of the jointly owned entity. The study examines two partner IJVs because of difficulties associated with analysing multiple partner IJVs, which may demonstrate significant differences from IJVs with two partners (Geringer, 1991). A distinct focus of the study is concentration on partners from developed industrial economies (compared to a focus on partners in developing countries found in other studies).

The main objective of the study is to examine the core dimensions of joint venture activity - strategic motives, partner selection criteria, management control and performance outcomes. The background literature, definition and operationalization of variables, and research questions of the study are detailed in each of the respective chapters that follow. Essentially, the study is of an empirical nature and broadly comprises an analysis of primary data obtained from senior managers in each element of the IJV system - both parents and IJV management - by means of personal interviews and self-administered questionnaires. The research methods of the study and sample characteristics are set out in Appendix 1. Outlines of the sample IJVs are in Appendix 2.

Chapter 2 examines motives and performance. The motives for IJV formation are identified, making a broad distinction between market entry motives and non-market entry motives. Contrary to the propositions advanced, the study finds that (i) measures of performance of the sample of IJVs are not based on a broad set of criteria but are based largely on financial criteria, and (ii) partners which have broadly different motives for the formation of the IJV do not adopt different performance criteria. In line with expectations, the study finds that the level of satisfaction of IJV performance tends not to vary with underlying motives for IJV formation.

Chapter 3 builds on prior research by investigating partner selection in IJVs through an examination of the nature of task-related and partner-related selection 
criteria. Findings indicate that task-related selection criteria reflect resource complementarity, with partners displaying a greater awareness of resource complementarity than the IJV managers. The relative importance of the degree of favourable past association between partners appears to be a function of the number of prior ties between partners. Trust between top management teams is the most important element of partner-related selection criteria. The status indicators of reputation, financial stability and to a lesser extent the partner company's size are also important elements of partner-related selection criteria. There is some support for the view that there is greater consensus between partner groups on the importance of the set of partner-related selection criteria than on the different factors of task-related selection criteria.

Chapter 4 investigates the form of management control exercised by parent firms over their international joint ventures. The main goal of the chapter is to identify the dimensions of control for a sample of UK-Western European IJVs in terms of the mechanisms of control, the extent of control and the focus of control. The main findings are: (1) that IJV partner firms seek to use an array of mechanisms to ensure control; (2) that different partners to an IJV will seek to influence IJV management through different mechanisms of control; (3) the extent of partner control is independent of the equity share of the partner, however, this finding may be largely conditioned by having a sample where in the majority of cases the equity share is equally split or nearly so; (4) partner firms will seek to concentrate on particular aspects of IJV control associated with their key skills and competencies.

Chapter 5 investigates approaches to decision making in international joint ventures from the perspectives of the transactions cost and resource based theories of the firm. In particular, the concept of autonomy in decision making is examined. The findings show that there are differences in the perception of autonomy between each of the parent firms, and between the parent firms and the IJV management. When we unpack the nature of autonomy in detail, it is found that IJV managers have greater degrees of operational autonomy than strategic autonomy and that decision making by IJV managers takes place within the context of constraints set within the IJV's business plan. This confirms the transaction cost theory which posits that key internal markets (for management, technology and capital) will be under parent control and also supports the resource based view that key capabilities are protected under the business plan established by the parent firms. The influence on IJV autonomy of the moderating variables IJV performance and IJV duration are also examined.

Chapter 6 identifies the key lessons of managing IJVs from the perspectives of IJV experienced partners and managers. Broadly, the response categories are grouped into three distinct areas of learning: the management of the IJV formation process, management of the boundary relationship between partners, and the management of the operation of the IJV. The chapter elucidates 
the lessons regarding these three areas of IJV management and provides a set of propositions for future research.

Chapter 7 provides new perspectives on the partnering skills needed for success in IJVs. Four categories of skills are analysed: inter-partner skills, managing the IJV managers, the 'upward management' skills of IJV managers managing the 'parent' partners, and those of managing the IJV itself. The chapter presents a matrix to examine the four categories of skill in the context in which each is used. Serving both as an analytical device and a diagnostic tool, this matrix offers results that have important implications for the management of IJVs with regard to the selection and training of managers and the inculcation of the skills required for each level of operation.

Chapter 8 replicates and extends a number of findings regarding performance assessment of IJVs. Findings support the growing evidence that while IJV objective performance measures and IJV subjective performance measures are positively correlated, they actually measure different phenomena. Findings show that the subjective performance assessment of one element of the IJV (partners or IJV management) matches that of the other elements, and that each element of the IJV has a good perception of the performance evaluation of the other elements. Correlations between partners' assessments of IJV performance are stronger in IJVs involving parents with similar national cultures when culture difference is measured by way of culture clusters, but not when cultural difference is measured by the Kogut-Singh index of cultural distance. Similarly, correlations between UK partners' assessment of IJV performance and the IJV management's assessment of performance are stronger in IJVs involving parents with similar national cultures when culture difference is measured by way of culture clusters, but less so when measuring cultural difference by the Kogut-Singh index of cultural distance.

Chapter 9 examines the extent to which differences in culture pose a problem to the management of IJVs and in particular whether national cultural differences or corporate cultural differences are more important in contributing to different views on the management of the IJV. The findings show that while cultural differences do exist they are not severe enough to cause significant problems for the management of the IJVs. Where problems do exist it was not firmly established whether national culture differences or corporate cultural differences were the chief cause of problems in managing the IJV.

A summary and conclusions from the whole study are provided in Chapter 10.

\section{NOTE}

1. We are grateful to Alan Rugman for the original insight into this issue. 